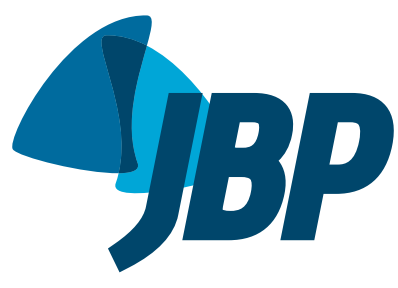

\title{
Back to the future: a case series of minimally invasive repair of pectus excavatum with regular instruments
}

\author{
Miguel Lia Tedde ${ }^{1, a}$, Silvia Yukari Togoro, ${ }^{1, b}$, Robert Stephen Eisinger ${ }^{2, c}$, \\ Erica Mie Okumura ${ }^{1, \mathrm{~d}}$, Angelo Fernandes ${ }^{1, \mathrm{e}}$, Paulo Manuel Pêgo-Fernandes ${ }^{1, \mathrm{f}}$, \\ Jose Ribas Milanez de Campos',
}

1. Departamento de Cirurgia Torácica, Instituto do Coração, Hospital das Clínicas, Faculdade de Medicina da Universidade de São Paulo - InCor/HCFMUSP - São Paulo (SP) Brasil.

2. University of Florida College of Medicine, Gainesville, FL, USA

a. (D) http://orcid.org/0000-0002-8178-4243

b. (D) http://orcid.org/0000-0002-1980-6595

c. (iD http://orcid.org/0000-0003-3191-2355

d. (iD http://orcid.org/0000-0002-1226-085X

e. (D) http://orcid.org/0000-0003-0645-4567

f. (D) http://orcid.org/0000-0001-7243-5343

g. (D) http://orcid.org/0000-0002-2385-7707

Submitted: 16 September 2017 Accepted: 10 April 2018

Study carried out in the Departamento de Cirurgia Torácica, Instituto do Coração, Hospital das Clínicas, Faculdade de Medicina da Universidade de São Paulo InCor/HC-FMUSP - São Paulo (SP) Brasil.

\begin{abstract}
Objective: Minimally invasive repair of pectus excavatum (MIRPE) is a surgical treatment for PE. During the procedure, a specialized introducer is used to tunnel across the mediastinum for thoracoscopic insertion of a metal bar. There have been reported cases of cardiac perforation during this risky step. The large introducer can be a dangerous lever in unskilled hands. We set out to determine the safety and feasibility of using regular instruments (i.e., not relying on special devices or tools) to create the retrosternal tunnel during MIRPE. Methods: This was a preliminary study of MIRPE with regular instruments (MIRPERI), involving 28 patients with PE. We recorded basic patient demographics, chest measurements, and surgical details, as well as intraoperative and postoperative complications. Results: Patients undergoing MIRPERI had Haller index values ranging from 2.58 to 5.56. No intraoperative complications occurred. Postoperative complications included nausea/vomiting in 8 patients, pruritus in 2, and dizziness in 2, as well as atelectasis, pneumothorax with thoracic drainage, pleural effusion, and dyspnea in 1 patient each. Conclusions: In this preliminary study, the rate of complications associated with MIRPERI was comparable to that reported in the literature for MIRPE. The MIRPERI approach has the potential to improve the safety of $P E$ repair, particularly for surgeons that do not have access to certain special instruments or have not been trained in their use.
\end{abstract}

Keywords: Funnel chest; Heart injuries; Thoracic wall; Intraoperative complications; Minimally invasive surgical procedures.

\section{INTRODUCTION}

Minimally invasive repair of pectus excavatum (MIRPE) was first performed in 1987 and was presented to the American Pediatric Surgical Association in 1997. In the procedure, specialized MIRPE tools are used in order to create a retrosternal tunnel for the placement of one or more metal bars to elevate the sternum. The metal bars remain in the chest until their removal several years later. ${ }^{(1)}$ This technique quickly gained popularity as an alternative to the conventional open repair technique, and the number of patients presenting for surgical correction of PE has increased exponentially. Although it is not without complications, MIRPE is currently considered the standard of care for the management of PE. ${ }^{(2)}$

Although bar displacement, infection, and pneumothorax are the most common complications of MIRPE, lifethreatening complications have also been reported. ${ }^{(3,4)}$ The riskiest step of the procedure, accounting for these severe complications, is the dissection of the mediastinum to create the tunnel. This step has been linked to many cases of cardiac injury requiring urgent thoracotomy or even resulting in death. ${ }^{(5,6)}$

To improve safety during mediastinal dissection, several technical modifications have been proposed. For instance, thoracoscopy is reportedly used in the majority $(83.7 \%)$ of cases. ${ }^{(7)}$ However, even with thoracoscopy-guided retrosternal tunnel dissection, cases of cardiac perforation and pericardial laceration have been described. Therefore, the potential for cardiac injury remains despite direct visualization of the pericardium. ${ }^{(8,9)}$ A recently published systematic review of the literature on life-threatening complications of MIRPE showed that there have been 12 published cases and 15 unreported cases of cardiac injuries, resulting in 9 deaths. ${ }^{(10)}$ Those numbers likely represent an underestimation.

Mediastinal dissection is dangerous primarily because of two incompatible aspects. The pectus introducer-a dedicated tool developed to create the tunnel-is a very long $(58.6 \mathrm{~cm})$ instrument that can become a dangerous lever in unskilled hands. At the same time, the retrosternal region, ordinarily a narrow anatomical space, is further narrowed in individuals with $P E$, because of the dorsal deviation of the sternum. Given this difficulty, the aim of the present study was to evaluate retrosternal tunnel dissection in a case series of patients undergoing MIRPE without the use of the pectus introducer. Instead, we opted for the exclusive use of a regular surgical instrument, a Crawford clamp. We refer to this technique as MIRPE with regular instruments (MIRPERI). 


\section{METHODS}

Between March of 2014 and August of 2016, 31 patients with PE were included in a prospective case series designed to evaluate the safety and effectiveness of MIRPERI. The study was conducted in the Thoracic Surgery Department of the Heart Institute of the University of São Paulo School of Medicine Hospital das Clínicas. The study was approved by the Research Ethics Committee of the Hospital das Clínicas (Registration no. UIN 2545), and all participating patients gave written informed consent.

The inclusion criteria followed those applied in our MIRPE practice, to include patients from 11 years old. Although we do not encourage the use of MIRPE in mature patients, we have no specific upper age limit, because it is an intraoperative decision: if the chest wall is too rigid, we convert to a combined (MIRPE and Ravitch) technique. Patients showing a complex (carinatum/excavatum) morphology were excluded, as were those with skeletal diseases, coagulation dysfunction, cutaneous diseases affecting the chest wall, or angiopathies, as well as those who were pregnant or obese, obesity being defined as a body mass index $>30 \mathrm{~kg} / \mathrm{m}^{2}$.

The standardized evaluation carried out for patient selection was the same as that routinely used at our facility to identify candidates for surgical treatment of PE. It involves clinical history taking, physical examination, and laboratory tests (including pulmonary function tests), chest X-rays, cardiac evaluation (electrocardiography and echocardiography), and a baseline low-dose computed tomography (CT) scan of the chest. Before the CT scans were acquired, patients were instructed to breathe normally. Low-dose CT scans were then performed with the patients in respiratory pause during quiet inspiration. From the CT scans acquired at the deepest point of the deformity, the following measurements were taken (Figure 1): the sagittal distance between the posterior aspect of the sternum and the anterior spine; the side-to-side distance; the sagittal distance of the right and left hemithoraces; the sternal rotation angle; and the sagittal distance between the posterior sternum in its hypothetical corrected position and the anterior spine, minus the distance between the posterior sternum in its actual position and the anterior spine. On the basis of those data, it was possible to calculate the Haller index, correction index, sternal rotation angle $\left(<30^{\circ}\right.$ vs. $\left.\geq 30^{\circ}\right)$, and chest wall asymmetry index. ${ }^{(11-13)}$

We have previously described in detail the MIRPE technique that we usually employ. ${ }^{(14,15)}$ To highlight the modifications that we propose, the main steps of the procedure are summarized. The patients are intubated with single-lumen tracheal tubes. The use of ventilation at lower volumes or with shorter periods of apnea precludes the need for double-lumen intubation. The skin is marked at the point of deepest depression on the midline and at the hinge point in each hemithorax. An incision is made laterally to the hinge points in each

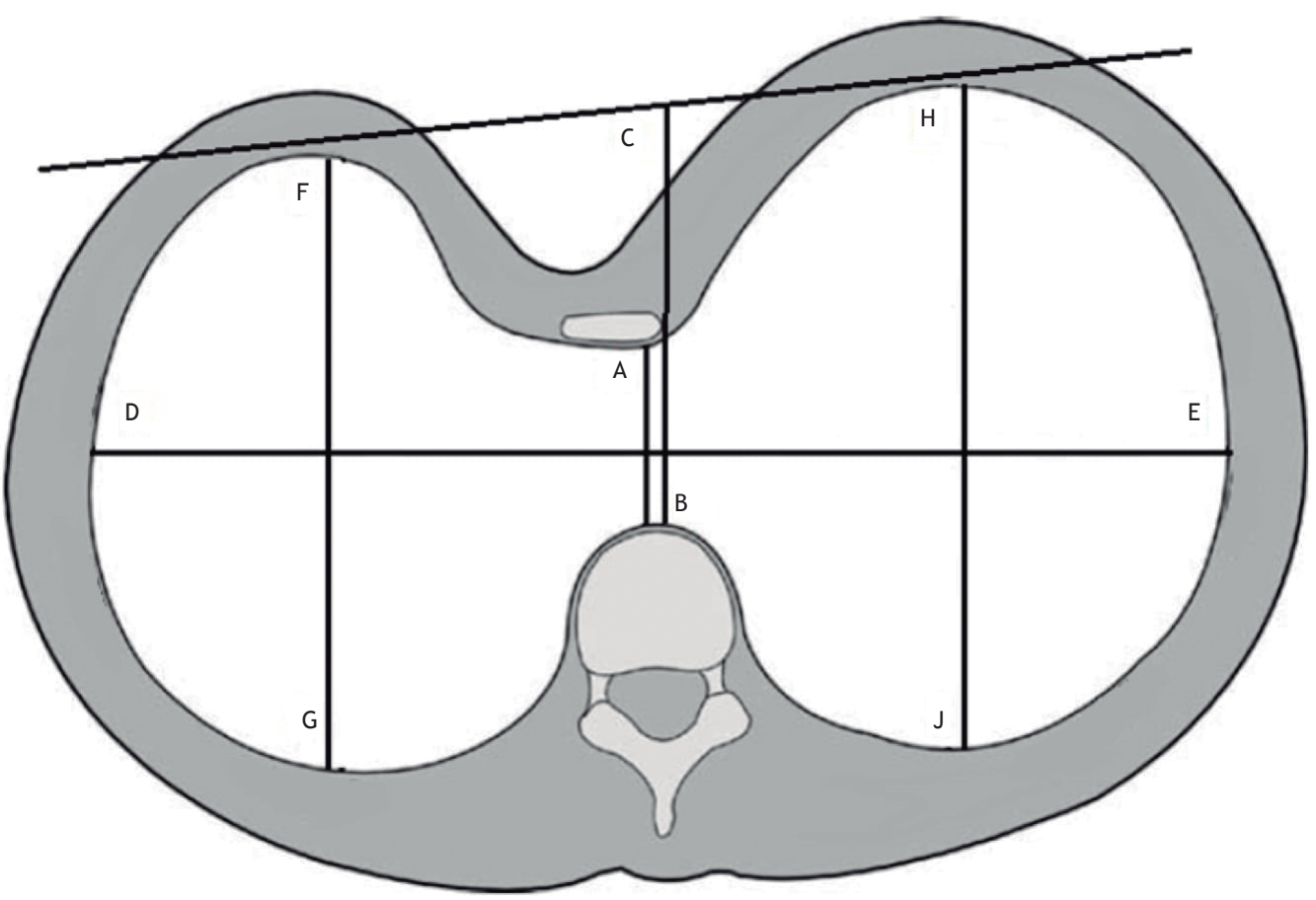

Figure 1. Thoracic schematic diagram of the thorax, with measurements: the sagittal distance between the posterior aspect of the sternum (A) and the anterior spine (B); the sagittal distance between the posterior sternum (C) in its hypothetical corrected position and the anterior spine (B), minus the distance between the posterior sternum in its actual position and the anterior spine (B); the side-to-side distance (D-E); the sagittal depth of the right and left hemithoraces ( $\mathrm{F}-\mathrm{G}$ and $\mathrm{H}-\mathrm{J})$; and the sternal rotation angle $(\mathrm{F}-\mathrm{C}-\mathrm{H})$. 
hemithorax, and a subcutaneous tunnel is created in the direction of the hinge points.

Although some surgeons prefer a right-to-left approach, we first enter the left thoracic cavity with the camera at the hinge point. Though the same incision, a 5.5-mm blunt trocar is introduced into the intercostal space immediately below the hinge point, and the camera is transferred to this lower space. A 24-cm long Crawford clamp is introduced at the hinge point, and, while the thoracoscope and the clamp are displacing the pericardium downward, the retrosternal tunnel is dissected with gentle movements (Figures 2 and 3).

As soon as the mediastinal midline is crossed, the thoracoscope is introduced on the right side and another Crawford clamp is used in order to displace the fat pad, thus avoiding injury to the major arteries that connect the internal mammary vessels and the anterior superior phrenic vessels that are found in $12.5 \%$ of right thoracic cavities and in $44.0 \%$ of left thoracic cavities. ${ }^{(16)}$

When the Crawford clamp crosses the fat pad and reaches the right hemithorax, a $28 \mathrm{~F}$ chest tube is placed through the hinge point incision inside the right hemithorax and it is brought back to the left hemithorax. The chest tube in the retrosternal tunnel represents a safe path to guide the pectus introducer or even the metal bar (Figure 4). The remainder of the surgery proceeds as usual.

To evaluate the safety and effectiveness of the MIRPERI technique, we recorded basic patient demographics, chest measurements, and surgical details. We also evaluated intraoperative and postoperative complications.

\section{RESULTS}

The basic characteristics of all 31 patients evaluated for inclusion in this case series are summarized in Table 1. In three cases (patients 3, 4, and 7), the defect was severe or the chest wall was too rigid. In those cases, we decided to use chondral cartilage resection through a midline incision before the metal bar was inserted under the sternum (combined MIRPE + Ravitch technique). The retrosternal tunnel was made with a combined bilateral approach, and those three cases were excluded from our analyses. Figure 5 demonstrates one such case.

Of the 28 patients that underwent MIRPERI and were included in the analysis, $6(21.4 \%)$ were female. In this patient sample, the mean age was $16 \pm 3$ years (range, 11-26 years) and the mean body mass index was $18.2 \pm 2.3 \mathrm{~kg} / \mathrm{m}^{2}$ (range, $14.0-22.3 \mathrm{~kg} / \mathrm{m}^{2}$ ). The mean Haller index was $3.73 \pm 0.87$ (range, 2.58-5.56) and was similar between males and females (3.80 \pm 0.90 and $3.47 \pm 0.71$, respectively). Of the 28 patients, $22(78.5 \%)$ received one bar and $6(21.4 \%)$ received two bars. The mean duration of anesthesia was 220 $\pm 38 \mathrm{~min}$ (range, 150-305 min). No intraoperative complications occurred.
In one case, a chest tube was used because of pneumothorax in the postoperative period. One patient developed pleural effusion that was detected by chest $X$-ray, although the effusion was minimal and resolved spontaneously. The other postoperative complications were nausea/vomiting in 8 patients, pruritus in 2, dizziness in 2, atelectasis in 1 , and dyspnea in 1 . No surgical site infections were observed. No other severe complications occurred. The mean hospital stay was $5 \pm 1$ days (range, 3-7 days).

\section{DISCUSSION}

In this study, we evaluated the safety and feasibility of MIRPERI, a slightly modified version of the MIRPE in which regular instruments are used for retrosternal tunnel dissection. In our sample of 28 patients, the complication rates were comparable to those reported in the literature for MIRPE, ${ }^{(4)}$ and there were no severe intraoperative or postoperative complications.

The proposal to use regular instruments to create a retrosternal tunnel for the correction of PE might sound like a throwback to some. In the early years of PE correction, the Nuss procedure was performed with regular surgical instrumental, although at that time the approach to dissection of the tunnel was from the right side and did not involve video assistance. The subsequent evolution of the technique was based on the development of dedicated instruments and the more recent development of tools that are even more specific. Therefore, it is understandable that the use of regular instruments would be considered regressive. However, that is not the case, as will be discussed below.

Although it is unquestionable that MIRPE with the Nuss procedure represented a major advancement in the surgical treatment of $P E$, it is also worrisome that the safety of the procedure is still debated, as well as that the real incidence of major and life-threatening complications remains unknown. ${ }^{(10,17)}$ The creation of the retrosternal tunnel, the most feared moment in the procedure, due to the risk of cardiac injury, continues to be the source of major complications. In addition to the technical difficulty of handling the large pectus introducer within the narrow mediastinal space, there are two other aspects that can complicate this step, one anatomic and the other epidemiological. From an anatomic standpoint, the heart is usually dislodged to the left in $\mathrm{PE}$, making the retrosternal tunnel dissection from the right to the left hemithorax seem illogical. From an epidemiological standpoint, except at centers with a large number of cases of PE, MIRPE is not a common procedure. As a result, a general thoracic or pediatric surgeon may not have had many opportunities to become skilled at using the pectus introducer.

Many surgeons have proposed technical modifications to reduce the risk of cardiac injury in MIRPE. These include using a subxiphoid incision to allow finger guidance to the mediastinal dissection ${ }^{(18,19)}$ and beginning the mediastinal dissection with the introducer 


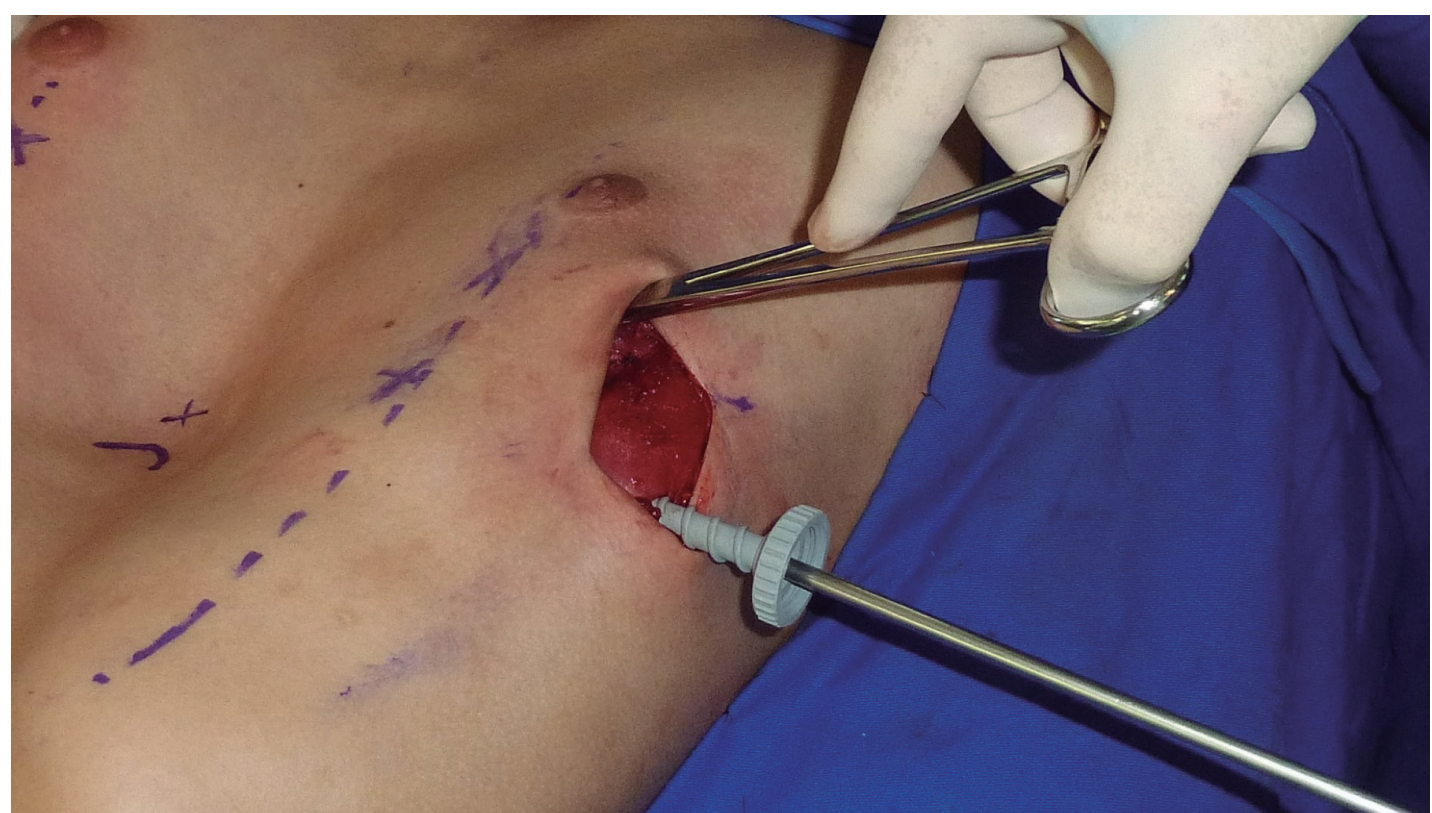

Figure 2. Tunnel dissection with regular instruments from the left side.

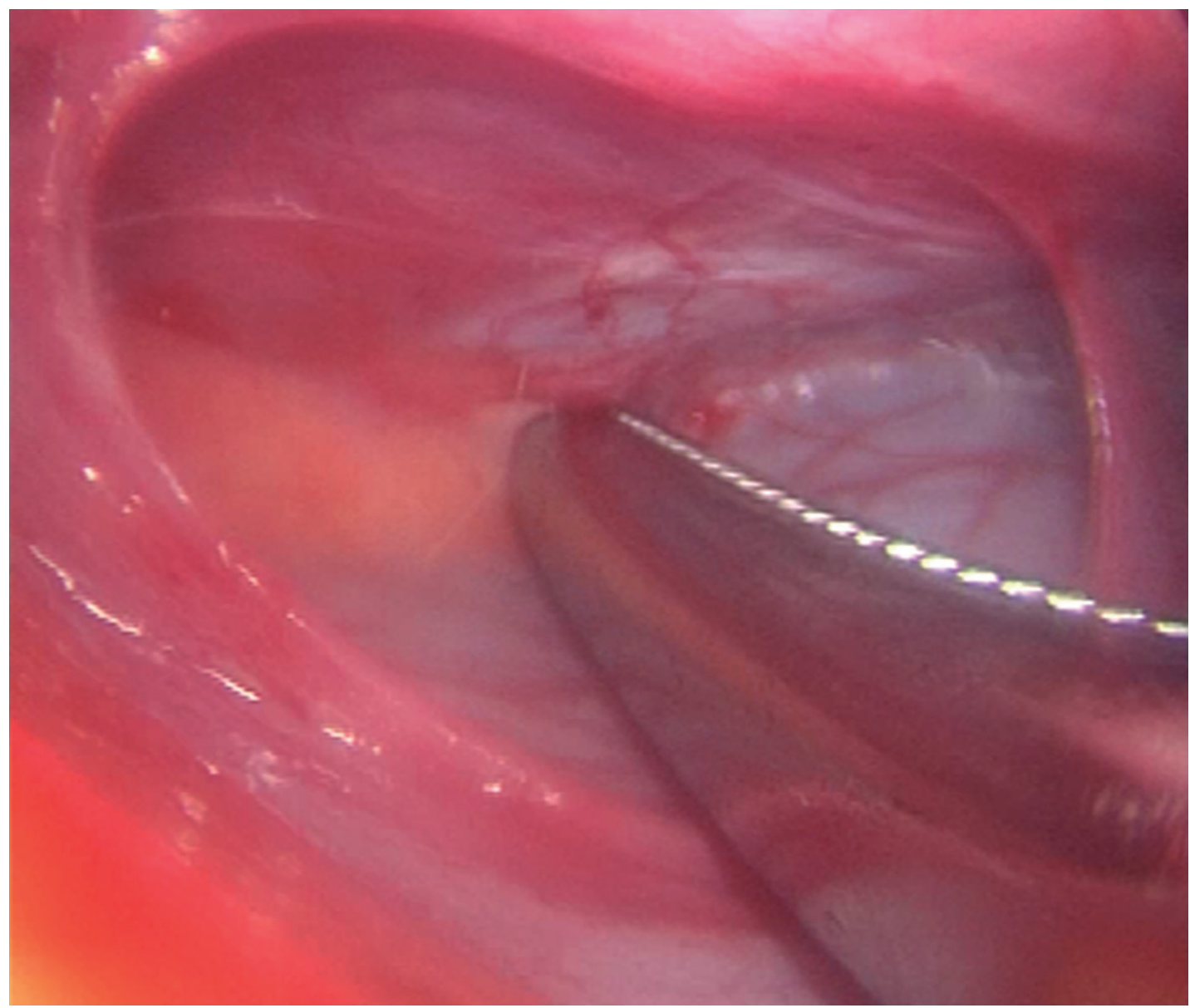

Figure 3. Thoracoscopic view of retrosternal tunnel dissection from the left hemithorax.

in a more cranial position and gradually proceeding distally. (20) However, the use of those techniques results in additional scars on the anterior chest wal that can be considered unacceptable, given that most PE patients elect to undergo this type of surgical procedure for cosmetic improvement. Another group 


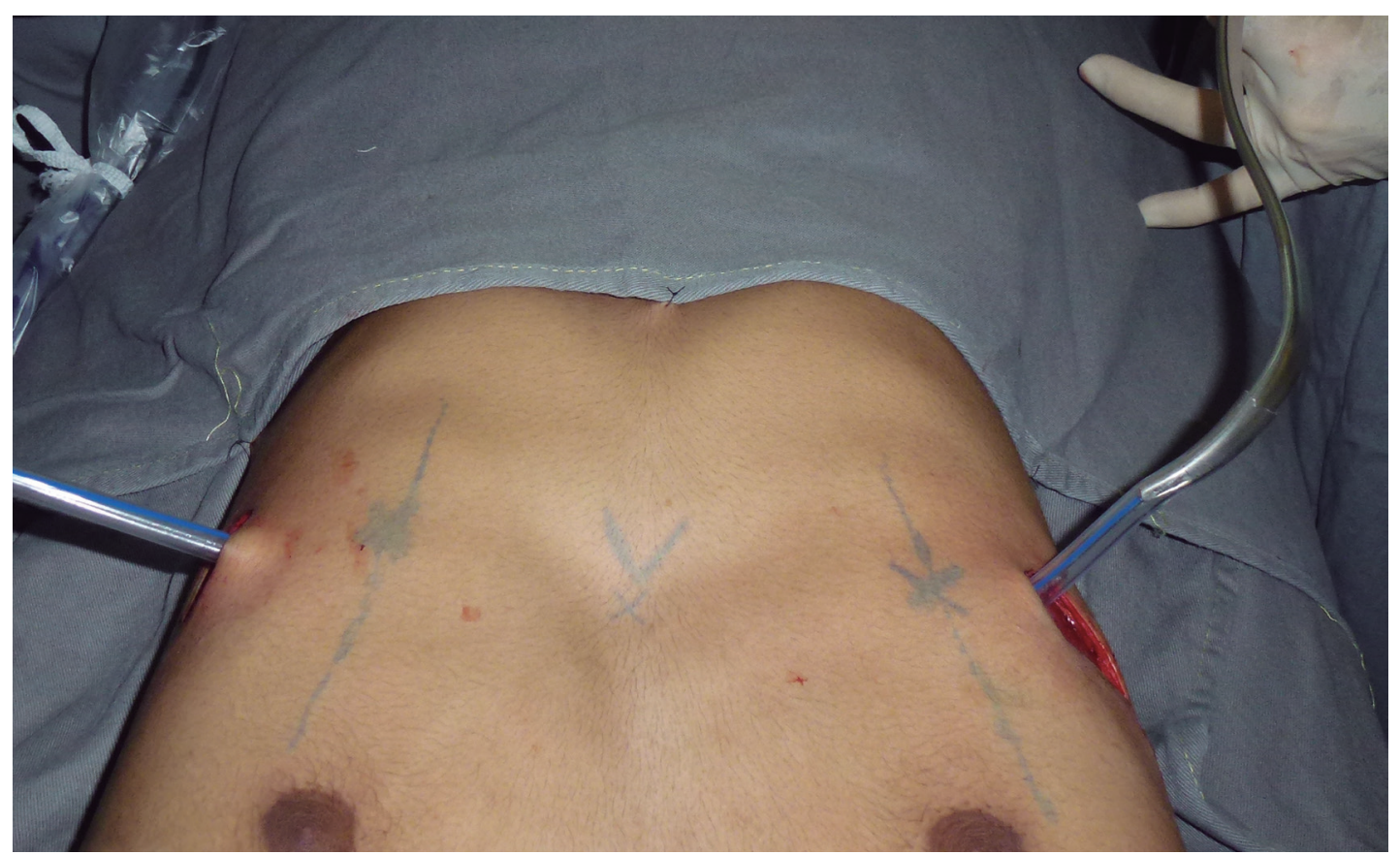

Figure 4. Chest tube passed through the retrosternal tunnel.

Table 1. Basic patient information, including gender, age, body mass index, Haller index, correction index, sternal rotation angle, number of metal bars utilized in the procedure, and length of the hospital stay.

\begin{tabular}{|c|c|c|c|c|c|c|c|c|}
\hline ID & Gender & $\begin{array}{l}\text { Age } \\
\text { (years) }\end{array}$ & $\begin{array}{c}\text { Body mass index } \\
\qquad\left(\mathrm{kg} / \mathrm{m}^{2}\right)\end{array}$ & $\begin{array}{l}\text { Haller } \\
\text { index }\end{array}$ & $\begin{array}{l}\text { Correction } \\
\text { index }\end{array}$ & $\begin{array}{c}\text { Sternal } \\
\text { rotation } \\
\left({ }^{\circ}\right)\end{array}$ & $\begin{array}{l}\text { Bars } \\
\text { (n) }\end{array}$ & $\begin{array}{c}\text { Hospital } \\
\text { stay } \\
\text { (days) }\end{array}$ \\
\hline 1 & M & 15 & 15.12 & 3.11 & 25.00 & 26 & 2 & 5 \\
\hline 2 & M & 20 & 20.20 & 2.58 & 20.75 & 13 & 1 & 6 \\
\hline $3^{*}$ & $M$ & 23 & 19.62 & 6.16 & 61.51 & 24 & 2 & 6 \\
\hline $4^{*}$ & $\mathrm{~F}$ & 14 & 11.15 & 30.38 & 90.18 & 19 & 1 & 8 \\
\hline 5 & M & 14 & 17.01 & 4.19 & 38.71 & 0 & 1 & 6 \\
\hline 6 & M & 17 & 19.97 & 4.52 & 43.14 & 26 & 2 & 3 \\
\hline $7^{*}$ & M & 28 & 20.65 & 2.97 & 35.23 & 25 & 1 & 5 \\
\hline 8 & M & 11 & 15.74 & 2.91 & 33.13 & 28 & 1 & 6 \\
\hline 9 & M & 15 & 17.10 & 5.53 & 52.46 & 30 & 2 & 5 \\
\hline 10 & $\mathrm{~F}$ & 13 & 15.05 & 3.50 & 32.95 & 36 & 1 & 6 \\
\hline 11 & M & 17 & 22.09 & 5.56 & 48.50 & 0 & 2 & 5 \\
\hline 12 & $M$ & 20 & 21.97 & 4.57 & 38.05 & 0 & 1 & 5 \\
\hline 13 & $\mathrm{~F}$ & 14 & 18.78 & 3.05 & 26.51 & 15 & 1 & 3 \\
\hline 14 & M & 20 & 17.53 & 2.73 & 20.85 & 13 & 1 & 6 \\
\hline 15 & M & 13 & 14.84 & 4.91 & 30.76 & 19 & 1 & 5 \\
\hline 16 & $\mathrm{~F}$ & 16 & 19.36 & 2.62 & 23.80 & 22 & 1 & 5 \\
\hline 17 & $M$ & 18 & 19.59 & 4.71 & 32.46 & 0 & 1 & 7 \\
\hline 18 & $M$ & 16 & 19.60 & 3.68 & 32.66 & 30 & 1 & 5 \\
\hline 19 & M & 15 & 18.08 & 4.65 & 46.88 & 30 & 1 & 5 \\
\hline 20 & M & 16 & 20.20 & 2.58 & 26.80 & 0 & 1 & 5 \\
\hline 21 & $M$ & 17 & 22.28 & 3.25 & 19.20 & 24 & 1 & 6 \\
\hline 22 & M & 12 & 13.96 & 3.38 & 31.24 & 21 & 1 & 6 \\
\hline 23 & $F$ & 12 & 15.43 & 3.11 & 20.31 & 25 & 1 & 6 \\
\hline 24 & $M$ & 16 & 17.26 & 3.22 & 30.21 & 0 & 1 & 5 \\
\hline 25 & $F$ & 24 & 19.69 & 4.61 & 48.35 & 0 & 2 & 5 \\
\hline 26 & $M$ & 26 & 19.66 & 3.14 & 25.73 & 21 & 1 & 4 \\
\hline
\end{tabular}

*Cases in which the defect was severe or the chest wall was too rigid, chondral cartilage resection through a midline incision therefore being performed before the metal bar was inserted under the sternum (combined MIRPE

+ Ravitch technique). 


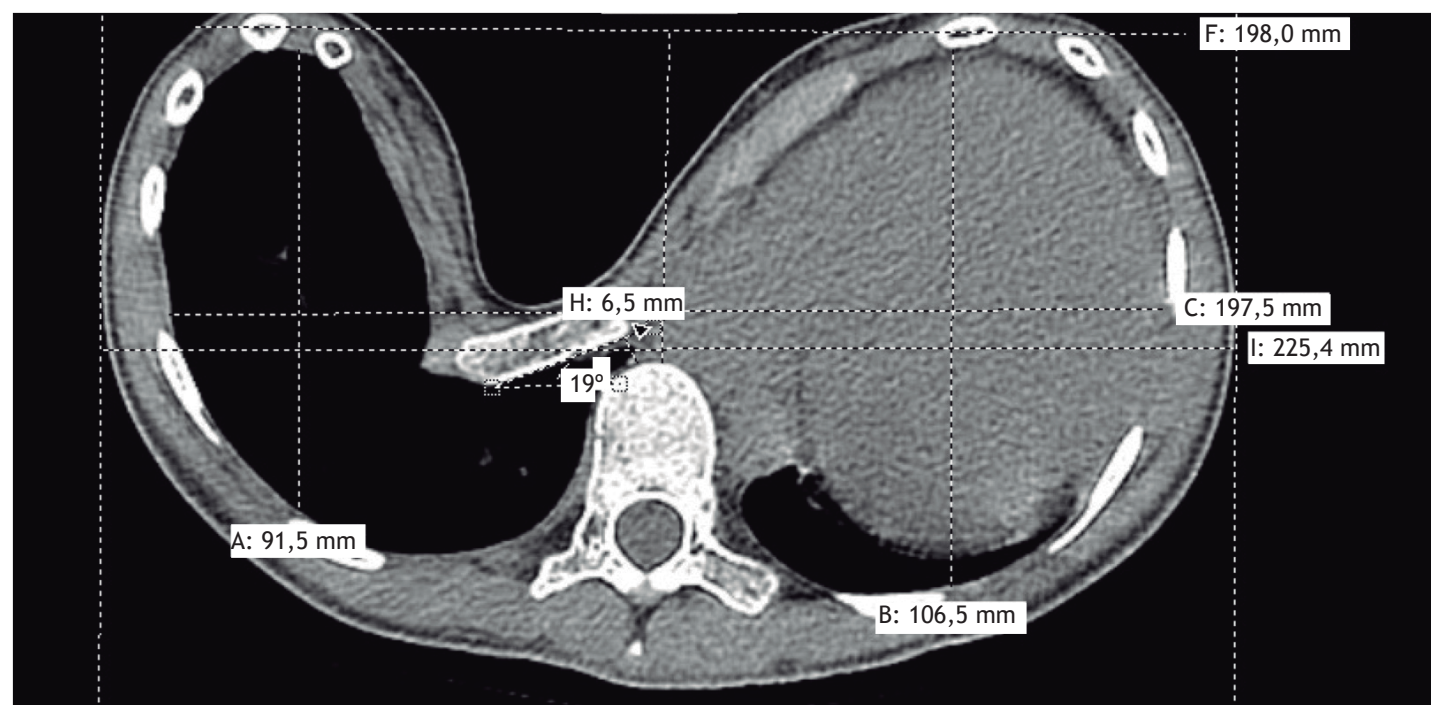

Figure 5. Computed tomography scan of patient 4 (Haller index of 30.3).

of modifications include the left-to-right dissection of the retrosternal tunnel and the use of bilateral thoracoscopy, as well as an approach guided by a specially designed videoscope. ${ }^{(15,21-23)}$ There is a reason for these modifications. Because the heart is dislodged to the left in PE patients, beginning the dissection from this side under left thoracoscopic visualization allows the surgeon to push the pericardium down and simultaneously continue the dissection.

Clearly, what most surgeons propose to avoid cardiac injury is some technique to promote sternal elevation. There are at least two technical modifications that employ newly dedicated devices for sternal elevation, one of which still relies on an additional subxiphoid incision. ${ }^{19,24)}$ The main problem with those techniques is that these dedicated retractors are usually available only to the group that developed them. There have also been seven reports describing sternal elevation maneuvers that employ non-dedicated devices, including the Kent retractor (Takasago Medical Co., Tokyo, Japan), the Rultract retractor system (Rultract Inc., $\mathrm{OH}, \mathrm{USA}$ ), and the Omni Crane System (Primemed, Seoul, South Korea). Although some are dependent on a complex sequence of steps to grasp the sternum before attaching it to the retractor, ${ }^{(25)}$ others rely on the use of a hook attached to the sternum ${ }^{(26-28)}$ or even the placement of wire sutures into the sternum to complete the elevation. ${ }^{(29,30)}$ Although these crane elevation techniques are celebrated as the safest way of facilitating the creation of the retrosternal tunnel, "grasping" the sternum for elevation is not free of complications. There has been one report of pinpoint perforation of the heart by a needle. (31) Another important consideration is that, even though these maneuvers to elevate the sternum involve the use of what could be called "traditional" retractors, those devices are not available on every surgical ward.

Because it is difficult to become skilled with the pectus introducer and most maneuvers proposed for the retrosternal tunnel creation are based on instruments not always available, we decided to test the feasibility of using only regular instruments during this surgical step. Although thoracoscopic instruments would represent the natural choice for this purpose, which was reserved as a "plan B", and we opted to use truly ordinary surgical instruments. That is why we elected to use the Crawford clamp in this study. Obviously, longer instruments, such as endoscopic tools, can be used instead.

We are not advocating against the use of the pectus introducer. Rather, this study provides preliminary data on a surrogate technique. Although we are aware that this suggestion might seem dispensable for surgeons who are experts in the treatment of $\mathrm{PE}$, the number of cardiac complications reported in literature during the treatment of this benign condition has convinced us to consider alternatives.

This study has some limitations. From a methodological point of view, it would be more appropriate to evaluate two groups: a control group of patients undergoing traditional MIRPE (with the pectus introducer) and another group of patients undergoing MIRPERI. Given that the complication rate of MIRPE is already well reported in the literature and that $P E$ repair is not a common surgical procedure, we choose to show in one case series that the procedure can be accomplished in the way we propose. Another limitation is the small number of patients. However, considering the relative rarity of $\mathrm{PE}$, we believe that 31 is a reasonable number of patients.

In conclusion, our results show that it is possible to dissect a retrosternal tunnel with regular instruments, even in patients with a Haller index as high as 5.6 (e.g., patient 11 in the present study). This technique can serve as an alternative for surgeons who feel unsure about using the pectus introducer. In addition, in this preliminary study of MIRPERI, the complication rates were comparable to those associated with conventional 
MIRPE. ${ }^{(4)}$ We believe that the MIRPERI approach, although it seems like a throwback, has the potential to improve the safety of PE repair, particularly for surgeons unaccustomed to the pectus-dedicated instruments or those who do not have access to all of the specific tools required for performing the standard procedure. Studies with larger patient samples are needed in order to confirm our findings.

\section{REFERENCES}

1. Nuss D, Kelly RE Jr, Croitoru DP, Katz ME. A 10-year review of a minimally invasive technique for the correction of pectus excavatum. J Pediatr Surg. 1998;33(4):545-52. https://doi.org/10.1016/S00223468(98)90314-1

2. Fallon SC, Slater BJ, Nuchtern JG, Cass DL, Kim ES, Lopez ME, et al. Complications related to the Nuss procedure: minimizing risk with operative technique. J Pediatr Surg. 2013;48(5):1044-8. https://doi. org/10.1016/j.jpedsurg.2013.02.025

3. Johnson WR, Fedor D, Singhal S. Systematic review of surgical treatment techniques for adult and pediatric patients with pectus excavatum. J Cardiothorac Surg. 2014;9:25 https://doi. org/10.1186/1749-8090-9-25

4. Kelly RE Jr, Mellins RB, Shamberger RC, Mitchell KK, Lawson $\mathrm{ML}$, Oldham KT, et al. Multicenter study of pectus excavatum, final report: complications, static/exercise pulmonary function, and anatomic outcomes. J Am Coll Surg. 2013:217(6):1080-9. https://doi. org/10.1016/j.jamcollsurg.2013.06.019

5. Leonhardt J, Kübler JF, Feiter J, Ure BM, Petersen C. Complications of the minimally invasive repair of pectus excavatum. J Pediatr Surg. 2005;40(11):e7-e9. https://doi.org/10.1016/j.jpedsurg.2005.07.033

6. Gips H, Zaitsev K, Hiss J. Cardiac perforation by a pectus bar after surgical correction of pectus excavatum: case report and review of the literature. Pediatr Surg Int. 2008;24(5):617-20. https://doi. org/10.1007/s00383-007-2097-1

7. Becmeur F, Ferreira CG, Haecker FM, Schneider A, Lacreuse I. Pectus excavatum repair according to Nuss: is it safe to place a retrosternal bar by a transpleural approach, under thoracoscopic vision? J Laparoendosc Adv Surg Tech A. 2011;21(8):757-61. https:// doi.org/10.1089/lap.2011.0035

8. Hebra A. Minimally invasive pectus surgery. Chest Surg Clin N Am 2010;10(2):329-39, vii.

9. Umuroglu T, Bostanci $K$, Thomas DT, Yuksel M, Gogus FY. Perioperative anesthetic and surgical complications of the Nuss procedure. J Cardiothorac Vasc Anesth. 2013;27(3):436-40. https:// doi.org/10.1053/j.jvca.2012.10.016

10. Hebra A, Kelly RE, Ferro MM, Yüksel M, Campos JRM, Nuss D. Life-threatening complications and mortality of minimally invasive pectus surgery. J Pediatr Surg. 2018;53(4):728-732. https://doi. org/10.1016/j.jpedsurg.2017.07.020

11. Haller JA Jr, Kramer SS, Lietman SA. Use of CT scans in selection of patients for pectus excavatum surgery: a preliminary report. $J$ Pediatr Surg. 1987;22(10):904-6. https://doi.org/10.1016/S00223468(87)80585-7

12. Cartoski MJ, Nuss D, Goretsky MJ, Proud VK, Croitoru DP, Gustin $T$, et al. Classification of the dysmorphology of pectus excavatum. J Pediatr Surg. 2006;41(9):1573-81. https://doi.org/10.1016/j. jpedsurg.2006.05.055

13. St Peter SD, Juang D, Garey CL, Laituri CA, Ostlie DJ, Sharp RJ, et al. A novel measure for pectus excavatum: the correction index. J Pediatr Surg. 2011:46(12):2270-3. https://doi.org/10.1016/j. jpedsurg.2011.09.009

14. Tedde ML, Campos JR, Das-Neves-Pereira JC, Abrão FC, Jatene FB. The search for stability: bar displacement in three series of pectus excavatum patients treated with the Nuss technique. Clinics (Sao Paulo). 2011;66(10):1743-6. https://doi.org/10.1590/S180759322011001000012

15. Tedde ML, de Campos JR, Wihlm JM, Jatene FB. The Nuss procedure made safer: an effective and simple sternal elevation manoeuvre. Eur J Cardiothorac Surg. 2012:42(5):890-1. https://doi. org/10.1093/ejcts/ezs442

16. Nagasao T, Takayama M, Miyamoto J, Ding W, Jiang H. Anatomical study of the thorax for the safe performance of the Nuss procedure for pectus excavatum. Thorac Cardiovasc Surg. 2011;59(1):34-9 https://doi.org/10.1055/s-0030-1249922

17. Sacco-Casamassima MG, Goldstein SD, Gause CD, Karim $O$ Michailidou M, Stewart D, et al. Minimally invasive repair of pectus excavatum: analyzing contemporary practice in 50 ACS NSOIPpediatric institutions. Pediatr Surg Int. 2015;31(5):493-9. https://doi. org/10.1007/s00383-015-3694-z

18. St Peter SD, Sharp SW, Ostlie DJ, Snyder CL, Holcomb GW 3rd Sharp RJ. Use of a subxiphoid incision for pectus bar placement in the repair of pectus excavatum. J Pediatr Surg. 2010;45(6):1361-4 https://doi.org/10.1016/j.jpedsurg.2010.02.115

19. Johnson WR, Fedor D, Singhal S. A novel approach to eliminate cardiac perforation in the nuss procedure. Ann Thorac Surg. 2013;95(3):1109 11. https://doi.org/10.1016/j.athoracsur.2012.10.016

20. Ohno K, Nakamura T, Azuma $T$, Yamada H, Hayashi H, Masahata K. Modification of the Nuss procedure for pectus excavatum to prevent cardiac perforation. J Pediatr Surg. 2009;44(12):2426-30. https://doi. org/10.1016/j.jpedsurg.2009.09.006

21. Palmer B, Yedlin S, Kim S. Decreased risk of complications with bilateral thoracoscopy and left-to-right mediastinal dissection during minimally invasive repair of pectus excavatum. Eur J Pediatr Surg. 2007;17(2):81-3. https://doi.org/10.1055/s-2007-965012

22. Park HJ, Jeong JY, Jo WM, Shin JS, Lee IS, Kim KT, et al. Minimally invasive repair of pectus excavatum: a novel morphology-tailored, patient-specific approach. J Thorac Cardiovasc Surg. 2010;139(2):37986. https://doi.org/10.1016/j.jtcvs.2009.09.003

23. Cheng YL, Lee SC, Huang TW, Wu CT. Efficacy and safety of modified bilateral thoracoscopy-assisted Nuss procedure in adult patients with pectus excavatum. Eur J Cardiothorac Surg. 2008;34(5):1057-61. https://doi.org/10.1016/j.ejcts.2008.07.068

24. Takagi S, Oyama T, Tomokazu N, Kinoshita K, Makino T, Ohjim $H$. A new sternum elevator reduces severe complications during minimally invasive repair of the pectus excavatum. Pediatr Surg Int. 2012;28(6):623-6. https://doi.org/10.1007/s00383-012-3087-5

25. Kim D, Idowu O, Palmer B, Kim S. Anterior chest wall elevation using a T-fastener suture technique during a Nuss procedure. Ann Thorac Surg. 2014:98(2):734-6. https://doi.org/10.1016/j. athoracsur.2013.12.077

26. Rygl M, Vyhnanek M, Kucera A, Mixa V, Kyncl M, Snajdauf J. Technica innovation in minimally invasive repair of pectus excavatum. Pediat Surg Int. 2014;30(1):113-7. https://doi.org/10.1007/s00383-013-34350

27. Jaroszewski DE, Johnson K, McMahon L, Notrica D. Sterna elevation before passing bars: a technique for improving visualization and facilitating minimally invasive pectus excavatum repair in adult patients. J Thorac Cardiovasc Surg. 2014;147(3):1093-5. https://doi. org/10.1016/j.jtcvs.2013.09.049

28. Takahashi T, Okazaki T, Yamataka A, Uchida E. Usefulness of Kent retractor and lifting hook for Nuss procedure. Pediatr Surg Int 2015:31(11):1103-5. https://doi.org/10.1007/s00383-015-3764-2

29. Park HJ, Chung WJ, Lee IS, Kim KT. Mechanism of bar displacement and corresponding bar fixation techniques in minimally invasive repair of pectus excavatum. J Pediatr Surg. 2008;43(1):74-8. https://doi org/10.1016/j.jpedsurg.2007.09.022

30. Yoon YS, Kim HK, Choi YS, Kim K, Shim YM, Kim J. A modified Nuss procedure for late adolescent and adult pectus excavatum. World $J$ Surg. 2010;34(7):1475-80. https://doi.org/10.1007/s00268-010-04659

31. Jeong JY, Lee J. Use of needlescope and crane technique to avoid cardiac injury in Nuss procedure. Ann Thorac Surg. 2014;98(1):386-7 https://doi.org/10.1016/j.athoracsur.2013.11.054 